\title{
CONSENTIMENTO INFORMADO NA INVESTIGAÇÃO PSICOLÓGICA COM IMPUTÁVEIS E INIMPUTÁVEIS NO ÂMBITO DO ORDENAMENTO JURÍDICO PORTUGUÊS
}

\author{
Emília Tavares Marques e J. Pais-Ribeiro
}

INFORMED CONSENT IN PSYCHOLOGICAL RESEARCH WITH CITIZENS ABLE-TO-STAND-TRIAL AND NOT-GUILTY-BY-REASON-OF-INSANITY UNDER THE PORTUGUESE LEGAL

\section{RESUMO}

Neste ARTIGO, ENQUAdRADO NUMA INVESTIGAÇĀO MAIS AMPLA NA ÁREA DA PSICOLOGIA, QUE ENVOLVE IMPUTÁVEIS E INIMPUTÁVEIS, REALIZADA NUM ESTABELECIMENTO PRISIONAL em Portugal, pretendemos fazer uma breve revisão BIBLIOGRÁFICA SOBRE A UTILIDADE E A IMPORTÂNCIA DO CONSENTIMENTO INFORMADO NA PESQUISA, QUER COM CIDADÃOS LIVRES, QUER COM CIDADÃOS JURIDICAMENTE PRIVAdos de liberdade. Consideramos que todo O PROFISSIONAL DE SAÚDE, NOMEADAMENTE PSICÓLOGO, DEVE PUGNAR PELA OBEDIÊNCIA A FIRMES PADRÕES DE ÉTICA NAS INVESTIGACCÕES, INDEPENDENTEMENTE DO GRUPO QUE ESTEJA A ESTUdAR. COMEÇAMOS POR DEFINIR AS NOÇÕES DE DEONTOLOGIA E ÉTICA, E DEPOIS NOS DEBRUÇAMOS SOBRE OS PRINCÍPIOS ÉTICOS CONTEMPLADOS NO ORDENAMENTO JURÍDICO PORTUGUÊS SOBRE O CONSENTIMENTO INFORMADO, ENTRE OS QUAIS O RESPEITO PELA DIGNIDADE DA PESSOA, A COMPETÊNCIA, A RESPONSABILIDADE E A BENEFICÊNCIA E NÃO MALEFICÊNCIA.

PALAVRAS-CHAVE

ÉTICA; CONSENTIMENTO INFORMADO; PESQUISA.

\section{ABSTRACT}

IN THIS PAPER, FRAMED IN A BROADER RESEARCH IN THE FIELD OF PSYCHOLOGY THAT INVOLVES ABLE-TO-STAND-TRIAL AND NOT-GUILTY-BY-REASON-OF-INSANITY IN A PRISON IN PORTUGAL, WE INTEND TO BRIEFLY REVIEW THE LITERATURE ON THE USEFULNESS AND IMPORTANCE OF INFORMED CONSENT IN RESEARCH WITH FREE CITIZENS AND WITH CITIZENS LEGALLY DEPRIVED OF FREEDOM. WE BELIEVE THAT ALL HEALTH PROFESSIONALS, NAMELY PSYCHOLOGISTS, SHOULD STRIVE FOR COMPLIANCE WITH FIRM STANDARDS OF ETHICS IN RESEARCH, REGARDLESS OF THE GROUP BEING STUDIED. WE BEGIN, THEN, DEFINE THE CONCEPTS OF DEONTOLOGY AND ETHICS, AND THEN TURNING TO THE ETHICAL PRINCIPLES COVERED IN THE Portuguese LEgAL INFORMED CONSENT, INCLUDING RESPECT FOR HUMAN DIGNITY, COMPETENCE, RESPONSIBILITY AND KINDNESS AND NOT NONMALEFICENCE. WITHIN THIS FRAMEWORK, WE DISCUSS ISSUES THAT ARISE WHEN CITIZENS INFORMED CONSENT IN LEGALLY DEPRIVED OF THEIR LIBERTY: AND ATTRIBUTABLE INDICTMENT.

\section{KEYWORDS}

ETHICS; INFORMED CONSENT; RESEARCH.

\section{INTRODUÇÃO}

A realização de investigações em seres humanos, nomeadamente nas áreas da psicologia clínica e da saúde, é necessária para o aumento do conhecimento acerca do comportamento humano e consequente recurso/aplicação desse conhecimento na melhoria/adequação da prática profissional. Para tal, o psicólogo deve pugnar pela obediência a firmes padrões de ética nas investigações, independentemente de o seu 
trabalho incidir sobre cidadãos livres ou juridicamente privados de liberdade. Entendemos, então, que deverá dominar vários conceitos, designadamente o de consentimento informado, o qual se insere nas directivas éticas profissionais e assume especial importância na investigação com seres humanos, inclusive na área da Psicologia. Por esse motivo, consideramos importante definir o que entendemos por deontologia e ética, embora de forma sumária, para depois passarmos a uma abordagem mais alargada, mas não exaustiva, sobre questões relacionadas com o consentimento informado para fins de investigação, particularmente no que respeita ao ordenamento jurídico português.

\section{DeFiniçÃo de DeOnTOlogia E DE ÉTiCA}

As questões relativas ao consentimento informado na investigação em psicologia, independentemente de direccionada aos cidadãos livres ou juridicamente privados de liberdade, pressupõem noções de deontologia e ética. No entanto, não é nossa intenção fazer uma abordagem alargada a cada um desses conceitos, mas sim uma breve alusão à noção que cada qual encerra.

Começamos, então, pelo conceito de deontologia. Embora esse termo tenha sido introduzido em 1832 pelo filósofo inglês Jeremy Bentham, com a publicação da sua obra Deontologia ciência da moral (Suero, 2001), a sua origem procede etimologicamente do grego - déon, -déontos “dever", lógos "tratado" (Costa, 2005) - e se refere ao tratado dos deveres, ou seja, ao conjunto de princípios e regras de conduta inerentes a uma determinada profissão. Assim, podemos afirmar que a deontologia é a dimensão ética de uma determinada actividade profissional ou profissão.

Existem numerosos códigos de deontologia, sendo a sua regulamentação da responsabilidade das associações, conselhos ou ordens profissionais. Esses códigos assentam em pressupostos de declarações universais e procuram espelhar o teor ético nelas expresso, sendo adaptados às particularidades de cada país e de cada grupo profissional.

A definição de ética assume vários significados, entre os quais os relacionados com as noções de bem e mal, dos costumes, da moral (do grego éthos). Porém, para este artigo importa apenas a noção de ética como área do saber, que nesta acepção deriva da palavra grega êthos e se reporta "ao modo de ser, ao carácter, à realidade interior de onde provêm os actos humanos" (Guedes, 2006, p. 470). Assim, ao conjunto de princípios, regras e procedimentos obrigatórios pelos quais se regem a conduta/exercício da psicologia (ou de outro grupo profissional), bem como as sanções para o seu incumprimento, designamos ética, o qual normalmente incorpora o código de ética profissional. Em Portugal, de acordo com a lei vigente e após estabelecido esse código, os princípios éticos passam a ter a força que lhe confere o facto de serem definidos e aprovados pelas respectivas associações profissionais. 
Os psicólogos portugueses estão sujeitos a uma deontologia própria, reguladora da sua profissão, a qual está estabelecida na Lei n. 57/2008, de 4 de setembro de 2008, que criou a Ordem dos Psicólogos Portugueses (OPP), e lhe confere poderes legais para zelar pelo cumprimento do código de ética. Assim, no capítulo VI, essa Lei define a "Deontologia profissional”, a qual impõe aos psicólogos um conjunto de princípios gerais (art. 75), deveres gerais (art. 76), deveres para com a Ordem (art. 79) e deveres recíprocos entre colegas (art. 81), incompatibilidades (art. 78), e a obrigatoriedade do sigilo profissional "em tudo o que diga respeito a factos que sejam revelados pelo cliente no âmbito de quaisquer assuntos profissionais" (art. 79).

O primeiro Código Deontológico da Ordem dos Psicólogos Portugueses (CDOPP) acabaria por ser aprovado em 25 de março de 2011, por deliberação da Assembleia de Representantes da OPP. Foi publicado no Diário da República de 20 de abril de 2011, através do Regulamento n. 258/2011, no qual ficou definido que entrava em vigor no "dia seguinte ao da sua publicação" (art. $2^{\circ}$ ).

Logo no início do "Preâmbulo" do CDOPP está patente a abrangência dos princípios éticos, isto é, são extensíveis a "qualquer área de aplicação e contexto, com o objectivo de guiar os/as psicólogos/as no sentido de práticas de excelência, garantindo que a referência do exercício profissional é o máximo ético e não o mínimo aceitável”.

Contudo, na ausência deste Código, os psicólogos portugueses, de um modo geral, tiveram como referência o Ethical Principles of Psychologists and Code of Conduct, da American Psychological Association (APA) (Marques, Pais-Ribeiro, Alves e Neves, 2009; Pais-Ribeiro, 2002).

No entanto, num dos países de língua oficial portuguesa, o Brasil, foram criados pela primeira vez, em 1971, os Conselhos Federal e Regionais de Psicologia (Pereira e Neto, 2003), através da Lei 5766, de 20 de dezembro, que lhes conferia o poder de "orientar, disciplinar e fiscalizar o exercício da profissão de Psicólogo e zelar pela fiel observância dos princípios de ética e disciplina da classe” (art. $1^{\circ}$, cap. I), sendo o Conselho Federal de Psicologia (CFP) “o órgão supremo dos Conselhos Regionais, com jurisdição em todo o território nacional e sede no Distrito Federal” (art. $2^{\circ}$, cap. II). Esse passo na história da psicologia do Brasil possibilitou a criação do primeiro Código de Ética dos psicólogos brasileiros, em 1975, através da Resolução n. 8, de 2 de fevereiro, do CFP. Esse Código foi revisto em 1977 (decreto n. 79 822, de 17 de junho) para fixar, segundo Pereira e Neto (2003), as "normas de orientação e fiscalização do exercício profissional de psicólogo" (p. 25). Outros documentos foram saindo no âmbito do CEP, até que em 2005 foi aprovada a versão mais recente do Código de Ética Profissional do Psicólogo brasileiro (Resolução n. 010/05, de 21 de julho), que passou a entrar em vigor a partir de 27 de agosto desse mesmo ano.

Quer o Código Deontológico da Ordem dos Psicólogos Portugueses em Portugal (n. 1 dos "Princípios específicos"), quer o Código de Ética Profissional do 
Psicólogo fazem alusão ao consentimento informado, que a seguir trataremos, respectivamente no n. 1 dos "Princípios específicos" do primeiro documento e na alínea $b$ do artigo 16 do segundo. No entanto, no Brasil, encontramos ainda um outro documento que define directrizes para "a realização de pesquisa em psicologia com seres humanos”, isto é, Resolução n. 016/2000, de 20 de dezembro, do CFP, que dedica os artigos $4^{\circ}$ a $8^{\circ}$ ao consentimento informado.

\section{BREVE PERSPECTIVA HiSTÓRICO-EVOLUTIVA DE REGULAMENTAÇÕES INTERNACIONAIS SOBRE O CONSENTIMENTO INFORMADO}

A questão da necessidade do consentimento do doente tem-se colocado desde há longa data. No entanto, segundo alguns estudiosos, as primeiras questões jurídicas ligadas a esse tipo de consentimento foram levantadas na Inglaterra, nos finais do século XVIII (1767), quando um acto médico sem consentimento do doente, que teve como consequência a perda de uma das suas pernas, foi levado a um Tribunal e culminou na condenação dos médicos envolvidos (Marques et al., 2010; Rodrigues, 2001; Simões, 2010). Também a França foi palco de um julgamento em Tribunal, no terceiro quartel do século XIX (1859), que condenou médicos por "realizarem actos de pura experimentação sobre menores” (Marques et al., 2010; Pereira, 2004, p. 58).

Em 1931, surgiu na Alemanha a primeira legislação para regular novas terapêuticas e investigação em seres humanos - Directivas Relativas às Terapêuticas Novas e à Experimentação Científica com o Ser Humano. Estas directivas obrigavam ao consentimento prévio dos doentes, apesar de excluir os menores de 18 anos e os moribundos. Deixaram de ser aplicadas com a ascensão de Adolf Hitler ao poder, em 1933 (Marques et al., 2010; Pereira, 2004).

Apenas com o fim da $2^{\text {a }}$ Guerra Mundial a questão do consentimento informado viria a ser retomada. De facto, durante os julgamentos dos crimes contra a humanidade, no qual, entre outros, vários médicos nazistas foram condenados por experiências em seres humanos, foi elaborado o Código de Nuremberga (1947), no qual ficou consagrada "a doutrina do consentimento informado" (Rodrigues, 2001, p. 35), que está definida de forma clara logo no primeiro princípio desse código, que abaixo transcrevemos na íntegra, em virtude da sua importância histórica para esta temática:

1. O consentimento voluntário do ser humano é absolutamente essencial. Isto quer dizer que as pessoas sujeitas à experimentação devem ser legalmente capazes de dar o seu consentimento; devem exercer o livre direito de escolha sem qualquer intervenção de elementos de força, fraude, mentira, coerção, astúcia ou outra forma de restrição posterior; devem ter conhecimento suficiente do assunto em estudo para poderem tomar uma decisão. Esse último aspecto exige que sejam explicados às pessoas a natureza, a duração e o propósito 
da investigação; os métodos pelos quais será conduzida; os inconvenientes e os riscos esperados; os efeitos sobre a saúde ou sobre a pessoa do participante, que eventualmente possam ocorrer, devido à sua participação na experiência.

O dever e a responsabilidade de garantir a qualidade do consentimento assentam no pesquisador que inicia ou dirige a experiência ou se compromete com ela. Estes são os deveres e as responsabilidades pessoais que não podem ser delegados a outrem impunemente (The Nuremberg Code). ${ }^{1}$

Outros documentos internacionais se lhe seguiram, alguns dos quais se encontram referenciados no quadro cronológico 1 , no final deste artigo.

O Código de Nuremberga foi posteriormente aperfeiçoado em vários documentos que se lhe seguiram. No entanto, não cabe neste artigo fazer referência a todos esses documentos, pelo que apenas nos centraremos em alguns deles.

No âmbito da $18^{a}$ Assembleia da Associação Médica Mundial surgiu em 1964 a Declaração de Helsínquia que definiu orientações éticas na pesquisa médica em seres humanos em nível internacional, a qual já sofreu várias revisões até ao presente. Essa declaração instituía, entre outros, que é necessário obter o consentimento informado do sujeito objecto de investigação.

Outro documento importante emergiu nos Estados Unidos em 1974. Referimonos ao Relatório de Belmont - Ethical Principles and Guidelines for the Protection of Human Subjects of Research, elaborado naquele país. Esse relatório definia os limites entre a prática e a investigação, enunciava os princípios éticos básicos e as directivas relativas à aplicação, nomeadamente no que respeita ao consentimento informado, à avaliação de riscos e benefícios e à selecção dos sujeitos. Em Portugal, a Comissão Nacional para a Protecção de Seres Humanos Sujeitos a Investigação Biomédica e Comportamental adoptou esse Relatório em 1979 (Marques et al., 2010; PaisRibeiro, 2002).

A Declaração sobre a Promoção dos Direitos dos Doentes na Europa, elaborada em 1994, no âmbito da OMS, constitui mais um documento que visa salvaguardar direitos dos seres humanos que participem em investigações, bem como promover o respeito pelas pessoas e equidade em saúde.

No ano seguinte saiu um outro documento que visava a "protecção das pessoas singulares no que diz respeito ao tratamento de dados pessoais e à livre circulação desses dados", isto é, a Directiva 95/46/CE do Parlamento Europeu e do Conselho da União Europeia, tendo sido transposto para o ordenamento jurídico português através da Lei de Protecção de Dados Pessoais em 1998 (Decreto-Lei n. 67/98, de 26 de outubro).

Em 1997, foi realizada a Convenção para a Protecção dos Direitos do Homem e da Dignidade do Ser Humano face às Aplicações da Biologia e da Medicina, no âmbito do Conselho da Europa, a qual define, no artigo $4^{\circ}$ do capítulo I, que toda a intervenção, 
que inclui a investigação, no campo da saúde "deve ser efectuada na observância das normas e obrigações profissionais, bem como das regras de conduta aplicáveis ao caso concreto". Essa convenção também estabelece que toda a intervenção na área da saúde só pode ser realizada após o consentimento livre e esclarecido, que deverá ser antecedido de "informação adequada quanto ao objectivo e à natureza da intervenção, bem como às suas consequências e riscos", podendo "em qualquer momento, revogar livremente o seu consentimento" (art. 5, cap. II, a "Regra geral” relativa ao "Consentimento").

Essa convenção dedica o capítulo V à "Investigação científica” nas áreas da biologia e da medicina, dedicando o artigo 16 à "Protecção de pessoas que se prestam a uma investigação", e o artigo 17 à "Protecção de pessoas que careçam de capacidade para consentir numa investigação". Porém, o n. 5 do referido artigo 16 define que, para fins de investigação, o consentimento poderá ser revogado em qualquer momento pela pessoa que aderiu à mesma, desde que "prestado de forma expressa, específica e esteja consignado por escrito".

Em 1997, surge no âmbito da União Europeia, o Tratado de Amesterdão (Centro de Informação Europeia Jacques Delors, 2008), que estabelece no n. 3 do artigo 100, entre outros, que o campo da saúde assentará "num nível de protecção elevado, tendo nomeadamente em conta qualquer nova evolução baseada em dados científicos". Institui no n. 1 do artigo 152 que a acção da Comunidade incidirá, entre outros, "na melhoria da saúde pública e na prevenção das doenças e afecções humanas e na redução das causas de perigo para a saúde humana", que abrange a "luta contra os grandes flagelos". Para tal, fomenta a "investigação sobre as respectivas causas, formas de transmissão e prevenção [das doenças], bem como a informação e a educação sanitária [sobre as mesmas]", e incidirá na "redução dos efeitos nocivos da droga sobre a saúde, nomeadamente através da informação e da prevenção”.

Nas Directivas Éticas Internacionais para a Pesquisa Biomédica Envolvendo Seres Humanos, documento criado em 2002 pelo Council for International Organizations of Medical Sciences (CIOMS) em colaboração com a Organização Mundial de Saúde (OMS), põem ênfase na necessidade de justificação ética e da validade científica da investigação, no consentimento informado, no respeito pela vulnerabilidade de indivíduos, grupos, comunidades e populações sujeitos a pesquisa, pela confidencialidade, entre outros. Nesse documento é também evidenciada a "importância das leis nacionais, das circunstâncias sócio-económicas, da cultura, religião e tradições, bem como à recompensa em caso de danos ou morte do indivíduo sujeito à intervenção/investigação médica” (Marques e Pais-Ribeiro, 2009, p. 8).

A sétima Declaração de Helsínquia sobre os Princípios Éticos para a Investigação Médica Envolvendo Seres Humanos, elaborada em 2008 pela Associação Médica Mundial, embora defina princípios éticos para a investigação médica em pessoas, incentiva outros profissionais envolvidos em pesquisas com seres humanos a adoptarem esses princípios (n. 1 e 2 da sua “A. Introduction”), entre os quais, "proteger a dignida- 
de, a integridade, o direito à autodeterminação, privacidade e confidencialidade" (n. 11 dos "B. Basic principles for all medical research"). Acresce, ainda, entre outros, o seguinte: (a) "a responsabilidade pela protecção dos indivíduos sujeitos à pesquisa é do médico ou de outro profissional de saúde" e nunca dos investigados, "embora tenham dado o consentimento" (n. 16 dos Princípios básicos); (b) se a investigação envolver pessoas "desfavorecidas ou vulneráveis" da população/comunidade, esta só se justifica se for "sensível às necessidades e prioridades da saúde" dessa população e se os resultados da investigação beneficiarem também a mesma população (n. 17 dos Princípios básicos); (c) “o sujeito deve ser informado de [poder] recusar (...) ou de retirar o seu consentimento (...), a qualquer momento, sem represálias” (n. 24 desses Princípios); (d) se o sujeito for considerado incapaz, o consentimento deve ser obtido pelo seu representante legal, devendo ser respeitado nas suas limitações (n. 27 dos mesmos Princípios básicos).

Apesar dos documentos referenciados anteriormente incidirem sobre princípios da ética médica e de estes não serem sempre coincidentes com os princípios da ética em psicologia, alguns são passíveis de serem aplicados em ambas as áreas (PaisRibeiro, 2002).

De entre os países de língua oficial portuguesa, o Brasil, conheceu a criação do Conselho Federal de Psicologia (CEP) em 1971, pelo que práticas, procedimentos e normas na área da psicologia integram documentos do ordenamento jurídico brasileiro. Assim, no âmbito do Conselho Nacional de Saúde (CNS) brasileiro surgiu a Resolução n. 01 /88, de 13 de junho, que define as "Normas de pesquisa em saúde" (Calvetti, Ludwig, Redivo, Menegat, Müller, 2007; Goldim, 2003, 2007), fazendo menção a aspectos éticos envolvidos na pesquisa na área da saúde, nomeadamente de cariz psicológico. Esse documento foi revogado pela Resolução n. 196/96, de 10 de outubro de 1996, a qual estabelece as Diretrizes e Normas Regulamentadoras de Pesquisas Envolvendo Seres Humanos, criando os Comités de Ética em Pesquisa (ligados às instituições de pesquisa) e a Comissão Nacional de Ética em Pesquisa (vinculada ao CNS do Ministério da Saúde brasileiro) (Filho, 2007; Goldim, 2011). A Resolução n. 196/96 foi revogada pela Portaria n.2048, de 3 de setembro de 2009, que aprovou o Regulamento do Sistema Único de Saúde.

Em 1997 foi publicada a Resolução n. 011/97, de 20 de outubro, para "disciplinar as pesquisas com técnicas e métodos não reconhecidos pela psicologia” (introdução à referida Resolução), obrigando o psicólogo a estabelecer um protocolo de pesquisa aprovado por CEP. Entretanto, em 2000, foi publicada a Resolução n. 016/2000, de 20 de dezembro, no âmbito do Conselho Federal de Psicologia, sobre a Pesquisa em Psicologia com Seres Humanos, definindo nomeadamente os riscos envolvidos na pesquisa e a necessidade do consentimento informado.

Em Portugal, até à publicação, em 2011, do Código Deontológico da Ordem dos Psicólogos Portugueses, esses profissionais, de uma forma geral, seguiam como 
orientação os princípios da American Psychological Association: Ethical Principles of Psychologists and Code of Conduct.

\section{Aspectos do ORdenAmento JURÍdico PORTUGUÊS RELACIONADOS COM O CONSENTIMENTO INFORMADO}

O consentimento informado na avaliação psicológica em saúde para efeitos de investigação em Portugal obedece às normas internacionais e está também consagrado em várias áreas ligadas ao nosso ordenamento jurídico, como no Direito Constitucional, no Direito Civil, no Direito Penal, no conjunto de leis dispersas que compõem o que designamos por Direito da Saúde e, sem dúvida, no Código Deontológico da Ordem dos Psicólogos Portugueses (Regulamento n. 258/2011, de 20 de abril), cujos princípios têm a força que lhe confere a Ordem dos Psicólogos Portugueses (criada pela Lei n. 57/2008, de 4 de setembro) e a referida legislação vigente do país (Marques et al., 2010).

De facto, a Constituição da República Portuguesa (CRP) define que as "normas e os princípios de direito internacional geral ou comum fazem parte integrante do direito português" (CRP, n. 1 do art. $8^{\circ}$ ), sendo que as "constantes de convenções internacionais regularmente ratificadas ou aprovadas vigoram na ordem interna após a sua publicação oficial e enquanto vincularem internacionalmente o Estado Português" (CRP, n. 2 do art. $8^{\circ}$ ). Estabelece, entre outros, direitos relativos à "Saúde" (cap. II, art. 64), à investigação científica (cap. III - alínea d) do n. 2 do art. 74) e à "Fruição e criação cultural” (art. 78, cap. III).

O Código Civil Português (CCP) (2009) reconhece direitos e deveres ou obrigações jurídicas aos titulares de personalidade jurídica, a qual se adquire com o nascimento e perdura até à morte (arts. 66 e 68). O artigo 130 do CCP reconhece a "plena capacidade de exercício de direitos" aos maiores de 18 anos de idade. Essa capacidade estende-se aos menores de 18 anos, mas com mais de 16 (CCP, art. 1612) "emancipados pelo casamento" (CCP, art. 132) com autorização "concedida pelos progenitores que exerçam o poder paternal, ou pelo tutor” (CCP, art. 1612). Também no CPP está consignado o direito especial de personalidade que se relaciona com "o direito à liberdade de vontade", e com a autodeterminação, vectores onde se funda o consentimento informado, isto é, a protecção dos "indivíduos contra qualquer ofensa ilícita ou ameaça de ofensa à sua personalidade física ou moral” (n. 1 do art. 70). Ainda estabelece a responsabilidade civil para quem violar os direitos de personalidade (n. 2 do art. 70), entre outros (Marques et al. 2010).

O Código Penal Português (CPP) define que o consentimento pode ser explícito através de "qualquer meio que traduza uma vontade séria, livre e esclarecida do titular do interesse juridicamente protegido", podendo "ser livremente revogado até à execução do facto” (n. 2 do art. 38). Também estabelece que a eficácia do consentimento 
apenas se verifica caso seja "prestado por quem tiver mais de 16 anos e possuir o discernimento necessário para avaliar o seu sentido e alcance no momento em que o presta" (n. 3 do art. 38), pois, caso contrário, isto é, se "menor de 16 anos ou psiquicamente incapaz", o consentimento deverá, entre outros, ser dado pelo representante legal (alínea $b$ do n. 3 do art. 142).

Segundo o CPP, a eficácia do consentimento verifica-se quando o doente é "devidamente esclarecido sobre o diagnóstico e a índole, alcance, envergadura e possíveis consequências da intervenção ou do tratamento" (art. 157). Esse artigo dispensa o consentimento caso o esclarecimento ao doente possa vir a pôr "em perigo a sua vida" ou seja susceptível "de lhe causar grave dano à saúde, física ou psíquica”.

Quanto à "Violação do segredo", o artigo 195 do CPP determina que quem sem consentimento o praticar "é punido com pena de prisão até 1 ano ou com pena de multa até 240 dias". Relativamente ao “Aproveitamento indevido de segredo", determina que quem o fizer sem consentimento e com isso causar prejuízo está sujeito ao mesmo tipo de punição. De referir, que no n. 1, o artigo 38 do CPP estabelece que, além do previsto a lei, "o consentimento exclui a ilicitude do facto quando se referir a interesses jurídicos livremente disponíveis e o facto não ofender os bons costumes". O n. 4 desse último artigo institui ainda o seguinte: "Se o consentimento não for conhecido do agente, este é punível com a pena aplicável à tentativa”.

Quanto ao "Consentimento presumido", o artigo 39 do CPP equipara-o ao consentimento efectivo (n. 1) e define que é aplicado "quando a situação em que o agente actua, permitir razoavelmente supor que o titular do interesse juridicamente protegido teria eficazmente consentido no facto, se conhecesse as circunstâncias em que este é praticado" (n. 2).

Relativamente ao conjunto de leis dispersas no ordenamento jurídico português relacionadas com o direito da saúde, começamos pela Lei de Bases da Saúde (LBS, Lei n. 48/90 de 24 de agosto). Apesar de esta Lei ser omissa à protecção de pessoas sujeitas à investigação, apoia "a investigação com interesse para a saúde, afirmando que deve ser estimulada a colaboração neste domínio, entre os serviços do Ministério da Saúde e as universidades, a Junta Nacional de Investigação Científica e Tecnológica e outras entidades, públicas ou privadas" (Base XVII, n. 1). Na Base XXII da LBS define "Ensaios clínicos" como sendo o estudo com medicamentos, cujas regras foram estabelecidas pelo Decreto-Lei n. 97/94 de 9 de abril, nomeadamente a de necessitar de prévio consentimento por parte do doente (Marques et al., 2010).

O Decreto-Lei n. 97/95, de 10 de maio, veio regulamentar as "Comissões de Ética para a Saúde", que "funcionam nas instituições e serviços de saúde públicos e unidades privadas de saúde” (art. $1^{\circ}$ ), nas quais prevê na sua composição vários profissionais, nomeadamente psicólogos (art. $2^{\circ}$ ).

A Lei n. 46/2004 de 19 de agosto, que estabelece o regime jurídico aplicável à realização de ensaios clínicos com medicamentos de uso humano, também avança 
com vários conceitos, que embora não se destinem à investigação na área da psicologia, nomeadamente clínica, podem estender-se a esta área, com as devidas adaptações. Entre eles contam-se o de "Boas práticas clínicas" (alínea f)), de "Investigador" (alínea i)), de "Participante" (alínea n)) e de "Consentimento livre e esclarecido" (alínea o). Esse último conceito remete para a decisão tomada pela "pessoa dotada de capacidade para dar o seu consentimento ou (...) [do] seu representante legal" que deve ser expressa de forma livre depois de "devidamente informada sobre a natureza, o alcance, as consequências e os riscos do ensaio" e "mediante declaração obrigatoriamente reduzida a escrito, datada e assinada". Essa Lei também prevê que caso a pessoa não esteja em condições de dar o seu consentimento por escrito, poderá fazê-lo oralmente "na presença de duas testemunhas" (alínea $o$ ).

O doente mental também foi contemplado no ordenamento jurídico português no que se refere à matéria do consentimento informado, através da Lei de Saúde Mental (LSM, Lei n. 36/98, de 24 de julho). Assim, estabelece que o "utente dos serviços de saúde" mental tem o direito de, entre outros, concordar ou recusar "a participação em investigações, ensaios clínicos ou actividades de formação” (n. 1, alínea $e$ do art. $5^{\circ}$, bem como que no caso de serem "menores de 14 anos" ou que "não possuam o discernimento necessário para avaliar o sentido e alcance do consentimento" os direitos de aceitação ou recusa "são exercidos pelos representantes legais" (n. 3 do art. $5^{\circ}$ ).

Ainda no âmbito da saúde mental foi publicado em 1999 o Decreto-Lei n. 35/99, de 5 de fevereiro, que "estabelece os princípios orientadores da organização, gestão e avaliação dos serviços de psiquiatria e saúde mental” (art. $1^{\circ}$ ). Esse Decreto define que "o órgão consultivo em matéria de saúde mental, ao qual compete emitir parecer e apresentar propostas e recomendações, a pedido do Ministro da Saúde ou por sua iniciativa" (n. 1, art. $3^{\circ}$ ), nomeadamente quanto à "formação e investigação em saúde mental”, é o Conselho Nacional de Saúde Mental, o qual contém, além de outros, dois psicólogos (n. 2 do art. $3^{\circ}$ ).

No que diz respeito à legislação portuguesa, a maioria dos diplomas "parece dispensar a prática do psicólogo do requisito do consentimento informado" e refere-se mais "à intervenção e não à investigação" (Pais-Ribeiro, 2002, p. 20), até ao recémcriado Código Deontológico dos Psicólogos Portugueses.

\section{Abordagem aOS PRincípios Éticos inerentes AO CONSENTIMENTO INFORMAdo PARA FINS DE INVESTIGAÇÃo EM PSiCOlogia, EM PorTugal}

O Código Deontológico dos Psicólogos Portugueses, à semelhança de códigos deontológicos de outros profissionais, contempla normas de investigação em seres humanos que exigem a obtenção do consentimento informado junto dos participantes, podendo 
o participante desistir em qualquer momento do processo. Consideramos que o principal objectivo do consentimento informado para efeitos de investigação é fornecer aos potenciais participantes e/ou aos seus representantes legais as informações necessárias para que possam fazer uma escolha autónoma e tomar uma decisão relativamente à sua participação ou não, de forma voluntária, após terem sido devidamente esclarecidos.

Os princípios inerentes ao consentimento informado estão definidos no Código Deontológico da Ordem dos Psicólogos Portugueses (Regulamento n. 258/2011, de 25 de março de 2011), os quais seguem os estabelecidos nos documentos internacionais e nacionais que versam sobre essa matéria, alguns dos quais foram atrás referidos. Assim, no CDOPP esse conceito encontra-se definido da seguinte forma: “... escolha de participação voluntária do cliente num acto psicológico, após ser-lhe dada informação sobre a natureza e curso previsível desse mesmo acto, os seus honorários (quando aplicável), a confidencialidade da informação dela decorrente, bem como os limites éticos e legais da mesma”.

O CDOPP é mais específico sobre a questão do consentimento informado. No entanto, apenas faremos referência aos aspectos que se prendem mais directamente com a investigação em psicologia: (a) que o consentimento informado pressupõe que o psicólogo garanta a compreensão da informação por parte do cliente, que inclui procedimentos, possíveis consequências, confidencialidade dos dados recolhidos e limitações ético-legais; (b) que o processo de obtenção do consentimento requer que o psicólogo clarifique e discuta as informações necessárias com o cliente, desde o início até ao fim da relação com o mesmo; (c) que a participação dos clientes deve ser voluntária, mesmo quando se está perante pessoas com limitações da sua autodeterminação, entre as quais as que apresentam "dificuldades cognitivas, estado de saúde mental ou imposições legais"; (d) que quando há "limites da autodeterminação" do cliente, o psicólogo deve pedir o consentimento informado ao representante legal do cliente, o qual não isenta o psicólogo de clarificar o seu papel, procurar o acordo com a pessoa e agir "de forma a promover os direitos e bem-estar" da mesma.

No que diz respeito à investigação, o CDOPP estabelece que os psicólogos devem ter em conta os princípios de respeito pela dignidade da pessoa, de competência, de responsabilidade e de beneficência e não maleficência, pelo que não devem sobrepor a vontade legítima de querer saber mais ou de produzir conhecimento científico aos interesses do participante, que se prendem também com legítimos valores humanos e sociais deste, devendo colocar em posição cimeira o seu bem-estar. Assim, partindo do CDOPP entendemos que a conduta dos psicólogos na investigação deve reger-se, em especial, pelos seguintes parâmetros: (1) por "Não causar dados" físicos ou psicológicos aos participantes; (2) pela "avaliação de potenciais riscos" e benefícios para o participante, quer antes de avançar ou não para a investigação, quer antes da decisão do sujeito em participar ou não na investigação; (3) pela sua "participação voluntária” e não sob qualquer forma de coacção ou a troco 
de compensação pecuniária ou outra; (4) pela "participação informada" sobre a investigação/participação; (5) pela "capacidade de consentimento", que poderá estar limitada pelo que referimos no parágrafo anterior na anterior alínea $c$ (no caso da investigação em curso pelos autores deste trabalho); (6) pelo "anonimato e confidencialidade dos dados recolhidos” exigidos e garantidos pelos investigadores, que se devem cingir ao estritamente necessário para a investigação; (7) pelos princípios mais nobres da "integridade científica"; (8) pela "apresentação de resultados verdadeiros" e não fraudulentos; (9) pela "comunicação de resultados das investigações de forma adequada para a comunidade científica e o público em geral”; (10) pelo "crédito autoral de ideias e trabalho nos termos devidos", que implica a originalidade dos trabalhos; (11) pela "responsabilidade por equipas de investigação", que envolve "a transmissão e cumprimento [das regras] a todos que com eles colaborem e ou estejam sob a sua supervisão”.

A conduta dos psicólogos portugueses obedece ainda aos princípios gerais atrás referidos e que estão clarificados no CDOPP. Tendo por base esse documento tecemos as seguintes considerações sobre cada um deles:

(1) "Respeito pela dignidade e direitos da pessoa." Consideramos que a dignidade da pessoa é o centro dos direitos fundamentais, é o pilar a partir do qual decorrem outros princípios, que tem de estar presente nas intervenções e nas investigações. Assim, o psicólogo além de respeitar o direito à dignidade deve também respeitar todos os direitos da pessoa sem distinção relativamente a outras, a não ser quanto à problemática/questões que apresentem. Esse princípio entronca no respeito pela autonomia e autodeterminação, pelo que o psicólogo, deve ter em conta as diferenças individuais de cada pessoa e aceitar incondicionalmente "as suas opiniões, preferências, credos e todas as características decorrentes da afirmação do seu carácter".

(2) “Competência.” Refere-se, essencialmente, ao exercício da psicologia tendo em conta "pressupostos técnicos e científicos da profissão" advindos de formação científica adequada e constantemente actualizada em termos teóricos e práticos especializados.

(3) “Responsabilidade.” Remete para a consciência/assumpção, por parte dos psicólogos, das possíveis consequências do seu trabalho junto "das pessoas, da profissão e da sociedade em geral", devendo dar o seu contributo em termos de bons resultados profissionais nessas dimensões e assumir a responsabilidade pela sua actividade.

(4) "Integridade." Diz respeito à "qualidade de quem revela inteireza moral”, o que exige aos psicólogos que sejam "fiéis aos princípios de actuação da profissão", que ajam de modo a "prevenir e evitar os conflitos de interesse" e que quando perante estes actuem "sempre de acordo com as suas obrigações profissionais". 
(5) "Beneficência e não maleficência."Trata-se de um dos princípios fulcrais do exercício da psicologia, que consiste em "ajudar o seu cliente a promover e a proteger os seus legítimos interesses”, de modo a que a intervenção ou investigação não o prejudique ou cause danos por acções ou omissões.

\section{CONSIDERAÇÕES FINAIS}

O consentimento informado é uma condição imprescindível para a investigação psicológica em seres humanos e legitima-a.

Defendemos que todos os cidadãos livres possuem diferentes graus de autonomia e de autodeterminação, assim como os cidadãos juridicamente privados de liberdade, quer sejam imputáveis ou inimputáveis. No entanto, como sabemos a autonomia dos que se encontram sob reclusão ou internados em meio prisional está, à partida, mais restringida em virtude da privação jurídica de liberdade. Apesar disso, o indivíduo não fica destituído de poder de forma livre decidir sobre a sua participação ou não no âmbito de uma investigação científica, desde que no momento em que é solicitado a participar esteja capaz de o fazer, não só em termos legais, cognitivos e emocionais, mas também, pensamos, desde que sinta que o psicólogo o respeita na sua condição actual (como pessoa sujeita a reclusão) e nas suas limitações, perceba a informação que o profissional lhe fornece e/ ou clarifique todas as dúvidas que tenha sobre a investigação versus riscos/benefícios da participação na mesma, bem como sinta que tem liberdade para reflectir e decidir de acordo com a sua avaliação pessoal.

A assinatura do termo de consentimento informado acaba por de alguma forma selar a autorização autónoma para a participação na investigação, embora o participante esteja ciente de que o pode desistir a qualquer momento do processo de recolha de dados.

Assim, consideramos que os princípios, directrizes e procedimentos eticamente instituídos para a investigação psicológica com cidadãos livres devem ser adoptados para com os cidadãos juridicamente privados de liberdade. À semelhança dos primeiros, o psicólogo deverá tratar estes últimos com dignidade, justiça e equidade, respeitá-los na sua autonomia, autodeterminação, decisão e direitos, assim como respeitá-los nas suas diferenças individuais e/ou limitações. Deverá ainda respeitar todos os trâmites inerentes ao processo de consentimento informado para fins de investigação e todos os procedimentos que esta envolve. No entanto, não devemos esquecer que o projecto de investigação antes de avançar, deverá passar inicialmente pelo crivo de todas as autorizações prévias necessárias à sua consecução. No caso da investigação em curso, junto dos imputáveis e inimputáveis, o projecto foi submetido à avaliação e aprovação das seguintes entidades: inicialmente pela Comissão Científica da instituição de ensino superior, depois pela Direcção-Geral dos Serviços 
Prisionais e, por fim, pela Comissão Nacional de Protecção de Dados. Antes, porém, de iniciarmos a investigação junto dos inimputáveis também apresentámos o projecto a ela subjacente ao Coordenador (médico psiquiatra) dos Serviços Clínicos e aferimos procedimentos.

: ARTigo APRovado (02/12/2012) : RECEBIDO EM 01/08/2011

\section{NOTAS}

1 The Nuremberg Code (1947), British Medical Journal, 1996; traduzido por Alexandra Neves (2009).

\section{REFERÊNCIAS BIBLIOGRÁFICAS}

ACADEMIA DAS CIÊNCIAS DE LISBOA (2001). Dicionário da Língua Portuguesa Contemporânea. Lisboa:Verbo. AMERICAN PSYCHOLOGICAL ASSOCIATION (2002). Ethical Principles of Psychologists and Code of Conduct [en liena]. Disponível em: www.tribunales.colpsic.org.co/documentos/APA_Ethics_code_2002.pdf. Acesso em: 9 jun. 2009.

ASSEMBLEIA DA REPÚBliCA (2005). Constituição da República Portuguesa [en linea]. Disponível em: www.parlamento.pt:80/Legislacao/Documents/constpt2005.doc. Acesso em: 23 abr. 2009. ASSEMBLEIA DA REPÚBLICA (2009). Revisões Constitucionais [en linea]. Disponível em: www.parlamento.pt/RevisoesConstitucionais/Paginas/default.aspx. Acesso em: 23 abr. 2009. BRITISH MEDICAL JOURNAL (1996). The Nuremberg Code (1947) [en linea], 7070 (313), 1448. Disponível em: www.cirp.org/library/ethics/nuremberg. Acesso em: 20 jun. 2009 CALVETTI, P. Ü.; LUDWIG, M. W. B.; REDIVO L. B.; MENEGAT, C. B., MülLER, M. C. (2007). A bioética na pesquisa em Psicologia [en linea]. Disponível em: www.psicologia.pt/artigos/ver_artigo.php?codigo=A0355. Acesso em: 20 nov. 2011.

CENTRO DE DOCUMENTAÇÃO JACQUES DELORS (2008). Tratado de Amesterdão que Altera o Tratado da União Europeia, os Tratados que Instituem as Comunidades Europeias e Alguns Actos Relativos a esses Tratados [en linea]. Jornal Oficial n. C 340 de 10 de Novembro de 1997. Disponível em: http://eur-

lex.europa.eu/pt/treaties/dat/11997D/htm/11997D.html. Acesso em: 9 jun. 2009.

COMISSÃO NACIONAL DE PROTECÇÃO DAS CRIANÇAS E JOVENS EM RISCO (2009). Declaração

Universal dos Direitos do Homem (1948) [en linea]. Disponível em:

www.cnpcjr.pt/preview_documentos.asp?r=1458\&m=PDF. Acesso em: 8 jun. 2009.

CÓDIGO DEONTOLÓGICO DA ORDEM DOS PSICÓlOGOS PORTUGUESES (2011). Diário da República, $2^{\text {a }}$ série, n. 78, 20 abr.

CÓDIGO CIVIL PORTUGUÊS (2008). Texto actualizado pela Procuradoria-Geral Distrital de Lisboa (disponível em: www.pgdlisboa.pt) e gentilmente cedido ao portolegal.com para publicação. Disponível em:

www.portolegal.com/CodigoCivil.html.

CÓDIGO PENAL PORTUGUÊS (2009). Direcção-Geral da Política de Justiça do Ministério da Justiça [en linea]. Disponível em: www.dgpj.mj.pt/sections/citius/livro-iv-leis-criminais/leis-criminais/codigo-penal/diplomasque-publicam. Acesso em: 2 mar. 2009

COSTA, M. F. (2005). Dicionário de Termos Médicos. Porto: Porto Editora. 
COSTA, J. A.; MElO, A. S. (1994). (Coord.) Dicionário da Língua Portuguesa. Porto: Porto Editora. COUNCIL FOR INTERNATIONAL ORGANIZATIONS OF MEDICAL SCIENCES (2002). International Ethical Guidelines for Biomedical Research Involving Human Subjects [en linea]. Disponível em: www.cioms.ch/ frame_guidelines_nov_2002.htm. Acesso em: 12 abr. 2009.

DECRETO N. 79 822/77, 17.06.1977. Brasília, Brasil. Disponível em: http://pol.org.br/legislacao/pdf/ decreto_n_79.822.pdf.

DECRETO-LEI N. 35/99, 05.02.1999. Diário da República Electrónico, n. 30 - Série I-A. Ministério da Saúde, Lisboa. DECRETO-LEI N. 97/94, 09.04.1994. Diário da República Electrónico, n. 83 - Série I-A. Ministério da Saúde, Lisboa. DECRETO-LEI N. 97/95, 10.05.1995. Diário da República Electrónico, n. 108 - Série I-A. Ministério da Saúde, Lisboa. DRUMOND, J. G. F. (2003). O princípio da beneficência na responsabilidade civil do médico. Bioética e Direito Médico, 11 (2), 159-68.

FERREIRA, F. A. G. (1990). História da Saúde e dos Serviços de Saúde em Portugal. Lisboa: Fundação Calouste Gulbenkian. FILHO, J. M. (2007, jan./fev.). Ética em pesquisa: Dez anos da Resolução CNS 196/96. Revista Brasileira de Reumatologia, 47 (1), 2-3 [en linea]. Disponível em: www.scielo.br/pdf/rbr/v47n1/a02v47n1.pdf. Acesso em: 20 nov. 2011

GOLDIM, J. R. (2003). Normas de pesquisa em saúde. Conselho Nacional de Saúde, Resolução n. 01/88, de 13.06.1988. Disponível em: www.ufrgs.br/bioetica/r01-88.htm. Acesso em: 20 nov. 2011.

(2007). A avaliação ética da investigação científica de novas drogas: a importância da caracterização adequada das fases da pesquisa. Revista do Hospital de Clínicas de Porto Alegre, 27 (1), 66-73. Disponível em: http://pt.scribd.com/doc/54173928/Goldim-Fases-Pesq-Novas-Drogas. Acesso em: 20 nov. 2011.

(2011). Breve histórico das diretrizes, normas e leis na pesquisa em seres humanos. Disponível em: www.ufrgs.br/bioetica/histpesq.htm. Acesso em: 20 de nov. 2011.

GUEDES, F. (Dir. geral). Dicionário Enciclopédico Português. Vol. 4. QUIDNOVI/Verbo.

LEI N. 36/98 de 24 de Julho (1998). Diário da República Electrónico n. 169 - Série I-A. Assembleia da República. Lisboa.

LEI N. 46/2004 de 3 de Março (2004). Diário da República Electrónico, n. 195 - Série I-A. Assembleia da República. Lisboa.

LEI N. 48/90 de 24 de Agosto (1990). Diário da República Electrónico, n. 19 - Série I-A. Assembleia da República. Lisboa.

LEI N. 57/2008 de 4 de Setembro (2008). Diário da República Electrónico, n. 247 - Série I-A. Assembleia da República. Lisboa.

LEI N. 67/98 de 26 de Outubro (1998). Diário da República Electrónico, n. 171 - Série I-A. Assembleia da República. Lisboa.

LEI N. 5766/71, de 20 de Dezembro (1971). Brasília, Brasil. Disponível em:

www.jusbrasil.com.br/legislacao/128508/lei-5766-71.

MARQUES, E. T. (2007). Da Loucura à Doença Mental. Da Doença Mental à Inimputabilidade. Avaliação de doentes esquizofrénicos internados numa clínica de psiquiatria em meio prisional. Maia: Edições Ismai.

MARQUES, E. T. (2008). Tratamento em meio prisional: desafios e problemas na prática clínica do psicólogo internamento de inimputáveis / intervenção em toxicodependentes. Psiquiatria, Psicologia \&Justiça, 2, 55-69. MARQUES, E. T.; PAIS-RIBEIRO, J. L.; ALVES, C.; NEVES, A. (2010). Consentimento informado na investigação psicológica na área da saúde: contributo das regulamentações (inter)nacionais. Psiquiatria, Psicologia \& Justiça, 3, 131-145, mar. 2010.

MARQUES, E. T.; PAIS-RIBEIRO, J. L. (2009). O detido: sujeito bio-psico-social. In Experiências e Intervenções em Psicologia da Saúde, CD-ROM, ISBN: 978-972-9341-79-3. Algarve: Universidade do Algarve - Faculdade de Ciências Humanas e Sociais, p. 1089-1105.

MORENO, A. (1961). Dicionário Complementar da Língua Portuguesa. 7. ed. Porto: Editora Educação Nacional. PAIS-RIBEIRO, J. L. (1999). Investigação e Avaliação em Psicologia e Saúde. Lisboa: Climepsi Editores. (2002). O consentimento informado na investigação em psicologia da saúde é necessário? Psicologia, Saúde \&Doenças, 3 (1), 11-22. (2008). Metodologia de Investigação em Psicologia e Saúde. Porto: Legis Editora Livpsic.

PEREIRA, A. G. D. (2004). O Consentimento Informado na Relação Médico-Paciente. Coimbra: Coimbra Editora. (2010). O consentimento informado na experiência europeia [en linea]. Disponível em:

http: / / estudogeral.sib.uc.pt/bitstream / 10316/14549/1/Aspectos\%20do\%20consentimento\%20informado\%20e\%20do\%2 Otestamento\%20Vital\%20Andr\%C3\%A9\%20Pereira\%20Ribeir\%C3\%A3o\%20Preto.pdf. Acesso em: 20 jun. 2010. PEREIRA, F. M.; NETO, A. P. (2003). O psicólogo no Brasil: notas sobre seu processo de profissionalização. Psicologia em Estudo, 8 (2), 19-27 [en linea]. Disponível em: www.scielo.br/scielo.php?pid=S1413-

$73722003000200003 \&$ script $=$ sci_arttext. Acesso em: 20 dez. 2010. 
RESOLUÇÃO N. 010/05, de 21.07 (2005). Brasília, Brasil. Disponível em: www.pol.org.br/pol/export/sites/ default/pol/legislacao/legislacaoDocumentos/codigo_etica.pdf.

RIBEIRO, J. L.; LEAL, I. (1998). Os limites da ética. In: V. Cláudio (Ed.). Psicologia e Ética - Actas do colóquio Europeu de Psicologia e Ética. Lisboa: ISPA, p. 117-126.

ROCHA, I. (2008). Códigos Penal e Processo Penal e Legislação Avulsa. Porto: Porto Editora.

RODRIGUES, J. V. (2001). O Consentimento Informado para o Acto Médico no Ordenamento Jurídico Português (Elementos para o Estudo da Manifestação da Vontade do Paciente). Coimbra: Coimbra Editora.

SIMÕES, L. C. S. (2010). Consentimento informado: o desafio médico-jurídico de nossos dias. Revista Brasileira de Ortopedia, 45 (2), 191-195 [en linea]. Disponível em: www.scielo.br/pdf/rbort/v45n2/15.pdf.

SOURNIA, J.-C. (1995). História da Medicina. Instituto Piaget.

SUERO, J. M. C. (2001). Ética Profesional en Ciencias Humanas y Sociales. Madrid: Huerga y Fierro Editores, S. L. The Belmont Report - Ethical Principles and Guidelines for the Protection of Human Subjects of Research (1974). [en linea]. Disponível em: www.fda.gov/ohrms/dockets/ac/05/briefing/2005-

4178b_09_02_Belmont\%20Report.pdf. Acesso em: 12 abr. 2009.

THE NUREMBERG CODE (1947). In: A. Mitscherlich; F. Mielke. Doctors of infamy: the story of the Nazi medical crimes. New York: Schuman, 1949. p. xxiii-xxv.

WORLD MEDICAL ASSOCIATION Declaration of Hensinki (2008). Ethical Principles for Medical Research Involving Human Subjects [en liena] em: Disponível em: www.wma.net/e/policy/pdf/17c.pdf. Acesso em: 9 jun. 2009 WORLD HEALTH ORGANIZATION (1994). A Declaration of Patients Rights in Europe, European Consultation on the rights of patients [en linea]. ICP/HLE 121. Disponível em:

www.who.int/genomics/public/eu_declaration1994.pdf. Acesso em: 9 jun. 2009. 
Quadro CRONOLÓGico 1

Alguns dos PRincipais documentos internaCiOnais ReleVAnTes.*

\begin{tabular}{|c|c|}
\hline ANOS & DOCUMENTOS \\
\hline 1947 & - CÓDIGO DE NUREMBERGA \\
\hline 1948 & - DECLARAÇÃO UNIVERSAL DOS DIREITOS HUMANOS \\
\hline 1950 & $\begin{array}{l}\text { • CONVENÇ̃̃O PARA A PROTECÇÃO DOS DIREITOS DO HOMEM E DAS LIBERDADES FUNDAMENTAIS } \\
\text { (CONSELHO DA EUROPA) }\end{array}$ \\
\hline 1964 & - DECLARAÇÃO DE HELSÍNQUIA I (ASSOCIAÇÃO MÉDICA MUNDIAL) \\
\hline 1974 & $\begin{array}{l}\text { - RELATÓRIO DE BELMONT - PRINCÍPIOS E DIRECTIVAS ÉTICAS PARA A PROTECÇ̃̃O DE SERES } \\
\text { HUMANOS SUJEITOS A INVESTIGAÇÃO, ADOPTADO POR PORTUGAL PELA COMISSÃO NACIONAL PARA } \\
\text { A PROTECC̣ÃO DE SUJEITOS HUMANOS DE INVESTIGAÇÃO BIOMÉDICA E COMPORTAMENTAL EM } 1979\end{array}$ \\
\hline 1983 & $\begin{array}{l}\text { - PRINCÍPIOS DE ÉTICA MÉDICA RELEVANTES PARA A PROTECC̣ÃO DE PRISIONEIROS CONTRA } \\
\text { A TORTURA (ONU) }\end{array}$ \\
\hline 1984 & - CARTA EUROPEIA DOS DIREITOS DOS PACIENTES (RESOLUÇÃO DE 19 DE JANEIRO) \\
\hline 1987 & $\begin{array}{l}\text { - CONVENÇÃO EUROPEIA PARA A PREVENÇÃO DA TORTURA E DAS PENAS E TRATAMENTOS } \\
\text { DESUMANOS OU DEGRADANTES (CONSELHO DA EUROPA) }\end{array}$ \\
\hline 1990 & $\begin{array}{l}\text { • RECOMENDAÇÃO N. R(90)3 DO COMITÉ DE MINISTROS AOS ESTADOS MEMBROS, RESPEITANTE } \\
\text { À INVESTIGAÇÃOO MÉDICA EM SERES HUMANOS }\end{array}$ \\
\hline 1993 & $\begin{array}{l}\text { - DIRECTIVAS ÉTICAS INTERNACIONAIS PARA A INVESTIGAÇÃO BIOMÉDICA EM SERES HUMANOS, } \\
\text { CRIADA PELO CONSELHO PARA AS ORGANIZAC̣ÕES INTERNACIONAIS DE CIÊNCIAS MÉDICAS } \\
\text { DA ORGANIZAÇÃO MUNDIAL DE SAÚDE }\end{array}$ \\
\hline 1994 & - DECLARAÇÃO DA PROMOC̣ÃO DOS DIREITOS DOS DOENTES NA EUROPA \\
\hline 1995 & $\begin{array}{l}\text { - DIRECTIVA 95/46/CE (DE } 24 \text { DE OUTUBRO) SOBRE A PROTECCุÃO DOS INDIVÍDUOS RELATIVAMENTE } \\
\text { AO PROCESSAMENTO DE DADOS PESSOAIS }\end{array}$ \\
\hline 1996 & $\begin{array}{l}\text { - CONVENÇÃO PARA A PROTECCCÃO DOS DIREITOS DO HOMEM E DA DIGNIDADE DO SER HUMANO } \\
\text { RELATIVAMENTE ÀS APLICAÇÕES DA BIOLOGIA E DA MEDICINA (CONSELHO DA EUROPA) }\end{array}$ \\
\hline \multirow[t]{3}{*}{1997} & - DECLARAÇÃO UNIVERSAL DO GENOMA HUMANO E DOS DIREITOS HUMANOS (UNESCO) \\
\hline & $\begin{array}{l}\text { - TRATADO DE AMESTERDÃO QUE ALTERA O TRATADO DA UNIÃO EUROPEIA, OS TRATADOS } \\
\text { QUE INSTITUEM AS COMUNIDADES EUROPEIAS E ALGUNS ACTOS RELATIVOS A ESSES TRATADOS }\end{array}$ \\
\hline & $\begin{array}{l}\text { - CONVENÇÃO PARA A PROTECÇÃO DOS DIREITOS DO HOMEM E DA DIGNIDADE DO SER HUMANO } \\
\text { FACE ÀS APLICAÇÕES DA BIOLOGIA E DA MEDICINA (CONSELHO DA EUROPA; PORTUGAL FEZ-SE } \\
\text { REPRESENTAR PELA MINISTRA DA SAÚDE) }\end{array}$ \\
\hline \multirow[t]{2}{*}{1998} & • DECLARAC̣ÃO IBERO-LATINO-AMERICANA SOBRE ÉTICA E GENÉTICA - MANZANILLO II \\
\hline & - CONVENÇÃO PARA OS DIREITOS DO HOMEM E DAS LIBERDADES FUNDAMENTAIS (CONSELHO DA EUROPA) \\
\hline 2001 & $\begin{array}{l}\text { - DIRECTIVA 2001/20/CE ( } 4 \text { DE ABRIL) SOBRE BOAS PRÁTICAS CLÍNICAS NO USO DE MEDICAMENTOS } \\
\text { (CONSELHO DA EUROPA) }\end{array}$ \\
\hline 2002 & $\begin{array}{l}\text { - DIRECTIVAS INTERNACIONAIS PARA A PESQUISA EM SERES HUMANOS, CRIADA PELO } \\
\text { CONSELHO PARA AS ORGANIZAC̣ÕES INTERNACIONAIS DE CIÊNCIAS MÉDICAS DA ORGANIZAÇÃO } \\
\text { MUNDIAL DE SAÚDE }\end{array}$ \\
\hline 2005 & - DECLARAÇÃO UNIVERSAL SOBRE BIOÉTICA E DIREITOS HUMANOS (UNESCO) \\
\hline 2008 & - DECLARAÇÃO DE HELSÍNQUIA VII (ASSOCIAÇÃO MÉDICA MUNDIAL) \\
\hline
\end{tabular}

* com baSE EM PAIS-RIBEIRO (2002); PEREIRA (2004); RODRIGUES (2001). 
572 : CONSENTIMENTO INFORMADO NA INVESTIGAÇÃO PSICOLÓGICA COM IMPUTÁVEIS E INIMPUTÁVEIS

\section{Emília Tavares Marques}

Av. da Boavista, n. 991 $5^{\circ}$ Dir.-Traseiras - 4100-128 Porto - Portugal

emiliapsiamail.telepac.pt

Rua Alfredo Allen - 4200-135

Porto - Portugal jlprafpce.up.pt
Mestre em Psicopatologia e Psicologia Clínica e Doutora em Psicologia (Clínica/Justiça) pela Faculdade de Psicologia e DE CIÊnCIAS dA EDUCAÇÃo dA Universidade do PoRTo

\section{J. Pais-Ribeiro}

Professor Associado com Agregação e Doutor em Psicologia pela faculdade de Psicologia e de Ciências dA Educação da Universidade do Porto 